This paper is part of the Proceedings of the $3^{\text {rd }}$ International Conference on Design, Construction, Maintenance, Monitoring and Control of Urban Water Systems

\title{
Drinking water catchment and minimum vital flow in torrential habitat
}

\author{
G. Ciaravino \& C. Ciaravino \\ Department of Civil, Environmental and Architectural Engineering, \\ University of Naples Federico II, Italy
}

\begin{abstract}
This paper analyses the problems related to drinking water catchment in a torrential river habitat. In this context, estimating the minimum vital flow (MVF) needed to ensure optimal conditions for the survival of local wildlife species is no simple task as the evaluation of both the MVF and the water balance in the catchment basin is dependent upon hydrological parameters whose extremely variable values often make anthropic intervention incompatible with optimal natural flow conditions. In the case examined here, river discharge measurements taken during a survey campaign to assess the state of the river during a period of low water flow are compared with the MVF value. This comparison reveals measured discharge values that are incompatibly low compared to those calculated by means of the usual methodologies adopted for estimating the MVF. On the other hand, however, the sustainability of the quantity of water collected from the basin is confirmed by the mean yield of the reference Hydrogeological Unit, by the relative potential of the aquifer and, therefore, by the potential of the spring itself. A solution is proposed which, although specific to this context, does constitute a more general methodological approach.
\end{abstract}

Keywords: drinking water catchment, $M V F$, torrential regime, water balance.

\section{Introduction}

The climatic changes that have become increasingly evident in recent years have convinced water system administrators and technical staff that greater attention needs to be paid to environmental problems, whether these are related to global phenomena or to events with a more modest impact. 
Moreover, the economic downturn of the past few years has also led public sector administrators to be more attentive to financial issues regarding the planning of public works and their efficient management. Thus, as far as the usage of water resources is concerned, laws, regulations and standards have been updated and enhanced so as to give greater consideration, both generally and economically, to water as a fundamental feature of the overall environment.

As a result, the priority function of drinking water catchment calls for a careful assessment of the water balance so as to ascertain the sustainability of the intervention with particular reference to the conservation of the environmental features of the area involved, something which has not been common practice in the past. In the case of bodies of water where catchment from springs or aquifers impacts on local species, it appears essential to determine the minimum vital flow (MVF).

The MVF is commonly defined as the flow - at any one moment and in each homogeneous stretch of the watercourse - that safeguards the physical characteristics of the body of water, the physicochemical properties of the water itself and the typical biocenoses of the local natural environment. Specifically, safeguarding the physical characteristics of the body of water is dependent on the maintenance of its natural evolutionary tendencies (in terms of both morphology and hydrology), even in the event of artificially created variations in head, flow and particle transport. Secondly, the physicochemical properties of water are safeguarded by conserving water quality over time and maintaining the watercourse's natural self-purification capacity. Finally, safeguarding the typical bioceneses of the natural environment is achieved by conserving the characteristic populations of the area in the long term while taking into consideration the various life stages of each species [1-6].

With reference to a stretch of water devoid of artificial systems regulating the natural flow $Q_{n}$, variable in time $t$, and indicating the MVF with $Q_{m v}$, two distinct cases can be envisaged:

a) a natural flow regime $Q_{n}$ which in the stretch of river in question is always greater than or equal to $\mathrm{Q}_{\mathrm{mv}}$ : in this regime, which can be defined as fluvial, the flow $Q_{c}$ which can be selected for catchment is: $Q_{c} \leq Q_{n}-Q_{m v}$;

b) a natural flow regime $Q_{n}$ which in the stretch of river in question falls below $\mathrm{Q}_{\mathrm{mv}}$ in non-negligible time intervals: in this regime, which can be defined as torrential, and in the above time intervals, we will have: $\mathrm{Q}_{\mathrm{n}} \leq \mathrm{Q}_{\mathrm{mv}}, \mathrm{Q}_{\mathrm{c}}=0$.

In the latter case the stretch of river is clearly subject to natural events that, in certain time intervals, will alter its natural balance: in fact, as a result of purely natural factors, the MVF could assume null values during periods of no rainfall or due to widespread permeability of the river bed in question.

The most complex scenario in terms of whether or not to site a drinking water catchment plant, therefore, clearly refers to a catchment basin in a natural river bed in torrential flow. The present paper analyses the issues related to drinking water catchment in such a case. 


\section{Concise analysis of the balance of water resources}

Estimating the water resource that can be used for catchment is dependent on the balance of both available and obtainable water resources and on the different uses envisaged in a context of compatibility and sustainability.

As a first step, it is worth determining whether the scheduled catchment is in fact compatible with the water balance of the system feeding the basin by estimating the MVF.

In particular, the sustainability of the envisaged catchment volumes must be confirmed by the mean yield of the reference Hydrogeological Unit. Using the following to indicate annual volumes [7]:

$\mathrm{R}_{\text {pot }}$ the potential water resource in the basin;

$\mathrm{R}_{\text {nat }}$ the natural water resource in the enclosed section of the basin;

$\mathrm{R}_{\mathrm{nc}}$. the non-conventional water resource in the basin;

$\mathrm{V}_{\text {est }}$ water volumes artificially transferred here from other basins;

$\Delta \mathrm{V}$ the difference between surface and ground water volumes in the basin;

$\mathrm{V}_{\text {trasf }}$ water volumes artificially transferred elsewhere;

$\mathrm{R}_{\text {sur }}$ the surface water resource available in the basin;

$\mathrm{R}_{\mathrm{gr}}$ the ground water resource available in the basin;

$\mathrm{V}_{\mathrm{MVF}}$ the minimum vital flow volume.

We can write the following relations:

$$
\begin{gathered}
R_{p o t} \leq R_{\text {nat }}+R_{n c}+V_{\text {est }} \pm \Delta V-V_{\text {tras }} \\
R_{\text {sur }}+R_{g r} \leq R_{\text {pot }}-V_{D M V}
\end{gathered}
$$

And using the following to indicate:

$\mathrm{F}_{\mathrm{civ}}$ the requirement for civil and drinking water uses (based on current conditions);

$\mathrm{F}_{\mathrm{agr}}$ the requirement for agricultural and other animal uses (based on current conditions);

$F_{\text {ind }}$ the requirement for industrial uses (based on current conditions);

$\mathrm{F}_{\mathrm{en}}$ the requirement for energy production uses (based on current conditions);

$\mathrm{F}_{\mathrm{mis}}$ miscellaneous requirements such as fishing, navigation, recreational, etc. (based on current conditions);

$\mathrm{R}_{\text {reu }}$ the water resource deriving from reuse of the basin;

$\mathrm{V}_{\text {ret }}$ water volumes returned to the basin from anthropic uses within the basin.

We can define a water balance relation:

$$
R_{\text {sur }}+R_{g r}-F_{c i v}-F_{\text {agr }}-F_{\text {ind }}-F_{\text {en }}-F_{\text {mis }}+R_{\text {reu }}+V_{\text {ret }} \geq 0
$$

which expresses the basin's water balance equilibrium conditions in terms of current usage and scheduled requirements. It is worth pointing out that the requirements or uses for civil and drinking water have priority over the others.

The analysis conducted allows us to define the value of the $\mathrm{Q}_{\mathrm{mv}}$ flow relative to the MVF as a constraint in terms of water catchment, and as a desirable (but not always obtainable) goal in terms of the river flow. If we consider the flow 
needed for aquatic life as one of the uses assigned to the water resource, the two cases mentioned in the introduction will be:

in case a) the $\mathrm{Q}_{\mathrm{mv}}$ flow represents a use that is prevalent over all others; in case b) the $\mathrm{Q}_{\mathrm{mv}}$ flow, or part of it, represents a recommended use to be compared with other uses, which might have priority (drinking water).

\section{Methodologies for estimating the MVF}

The MVF is an essential and substantial feature in the sustainable use of water indicated as an objective in the most important international scientific documents drafted at such historic meetings as the 1992 Dublin Conference and the 2003 Kyoto World Water Forum. This objective inspired the Water Framework Directive (WFD 2000/60/CE) issued by the European Community, after which the individual member countries drew up or confirmed standards and regulations on the sustainable use of water resources and, hence, for estimating the MVF. In order to estimate the MVF, a certain amount of characteristic information needs to be acquired, such as:

- the morphological, geological, climatic and hydrological features of the basin;

- $\quad$ the natural flow regime and the relative statistical features (mean, maximum and minimum values, duration curves, standard deviations, etc.);

- $\quad$ the geometric parameters of the river bed (shape and dimensions of the cross section, slope, sediment grain size, etc.);

- the hydraulic parameters of the stream: speed, head, particle transport, flow scale;

- $\quad$ the physicochemical properties identifying water quality;

- the biological parameters: extended biotic index (EBI), total microbial and escherichia coli load, aquatic flora and fauna and, in areas of outstanding natural beauty, flora and fauna of the riverbank;

- the waters removed from and discharged into to the watercourse, their relative flows, physicochemical properties and variability;

- $\quad$ the river functionality indices [8].

When information is initially lacking, the MVF can be estimated using simplified methodologies with subsequently measured or elaborated data.

Simplified methodologies fall into two categories:

I) regionalised methodologies;

II) experimental methodologies.

The first category I) estimates the MVF using concise parameters for the morphological and hydrological characteristics of the watercourse (the surface area and mean altitude of the basin subtended by the stretch in question, the mean monthly or yearly flow of the watercourse, flow duration values). These methodologies are essentially based on flow values that ensure the conservation of the habitat necessary for life and the results are subsequently generalised by more or less codified regionalisation techniques. Within this category we find the following methodologies, according to the quantities assumed as independent variables: 
- methods with morphological variables: these methods are based on the definition of a specific contribution (flow per surface area unit), where the independent variable is only the basin surface area. In many cases the method is greatly simplified by assuming the minimum unit contribution value to be a constant in a fairly large territorial area; however, as this makes it impossible to represent some particular situations, various correction factors are introduced;

- methods with simple hydrological variables: in these methods the minimum vital flow is usually made a function, by means of direct proportionality laws, of some characteristic flow values in the stretch considered, such as mean monthly flow, mean annual flow, etc.;

- methods with hydrological and morphological variables: these methods express a regression equation between the minimum vital flow and some hydrological and morphological variables of the basin, such as mean flow;

- methods with statistical variables: these methods are based on the determination of particular values for frequency or duration of flows. One example is based on the minimum mean flow over 7 days (mobile mean) with a return time $\operatorname{Tr} 10$ years $\left(\mathrm{Q}_{7,10}\right)$; others are based on the mean daily flow lasting 355 days in a year $\left(\mathrm{Q}_{355}\right)$ or on a function of the flow lasting 347 days $\left(\mathrm{Q}_{347}\right)$.

The second category II) is founded on experimental measurement techniques aiming to determine the optimal environmental conditions for one particular animal species for which the environmental suitability values are known. The measurements campaign makes it possible to build up curves that give - as a function of flow - the width of the riverbed or the hydraulic section suited to the survival of the reference species. In other words, identifying the functional maximum expressed in these curves provides the optimal flow value that must be guaranteed for the habitat. In particular, this category includes two types of methods:

- simple experimental methods: in which the MVF is correlated to the wet boundary or to the section width needed for the development of the species considered, assuming a simple criterion for assessing the suitability of the environmental parameters;

- complex experimental methods: in which certain continuous curves are used to assess the suitability of the environmental parameters; for instance, the microhabitats method provides a curve correlating the area considered available (a function of the flow, the mean velocity and the type of substratum) to the flow of the watercourse; the maximum on this curve corresponds to the optimal MVF value, as already mentioned above.

It should be noted that the Microhabitat method PHABSIM is frequently used for fluvial environments, while the Habitat Quality Index and Pool Quality Index are often used in torrential environments [9-13]. 


\section{Additional observations for estimating the MVF}

In technical practice, simplified methodologies are frequently employed to provide MVF estimation formulations that are not based on truly objective relations between the MVF and the characteristic ecological qualities of the body of water. In actual fact, every country has used its own laws, standards and guidelines to draw up structurally similar formulations based on a hydrological contribution that represents a starting threshold and which can generally be corrected upwards by means of coefficients identified through specific environmental conditions of the habitat in question. At present, therefore, there is no organic, internationally agreed methodology for estimating the MVF; simplified formulations have been proposed but these do not always indicate the scientific principles involved. By way of example, we below give the estimation criteria adopted by states in the Mediterranean area, whose territories often include torrential catchment basins.

Austria-Romania: the criteria for estimating MVF vary from case to case.

France: MVF assessment is regulated by fishing Law N ${ }^{\circ} 512$ of 20 July 1984, which can be summarised as follows:

- MVF is greater than $1 / 10$ of the mean annual flow over 5 years if the watercourse has a flow rate of less than $80 \mathrm{~m}^{3} / \mathrm{s}$;

- MVF is greater than 1/20 for higher flow rates.

Greece: a method has been adopted on the basis of the assessment of hydrological variables; in particular:

- $\quad$ MVF is $1 / 3$ of the mean summer flow.

Germany: the adopted method is based on statistical variables, and in particular on flow frequency or duration values which can be summarised as follows:

- $\quad$ MVF is equivalent to between $1 / 3$ and $1 / 2$ of the minimum continual flow of the watercourse; minimum continual flow = flow corresponding in the duration curves to the percentile of 355 days (this is a low-water flow identified as $\mathrm{Q}_{355}$ );

- MVF is equivalent to the minimum flow of 7 consecutive days with a 10 years return time $T_{r}$;

- MVF is equivalent to the minimum flow of 7 consecutive days with a 5 years return time $\mathrm{T}_{\mathrm{r}}$.

Portugal: the adopted method is based on the estimation of hydrological variables; in particular:

- MVF is greater than $1 / 10$ of the watercourse's mean flow.

Spain: the adopted method is based on statistical variables, and in particular on flow frequency and duration values which can be summarised as follows:

- MVF is greater than $1 / 10$ of the watercourse's mean flow;

- For watercourses inhabited by trout, the highest value obtained from the following formula must be applied:

- $\mathrm{MVF}=0.35 \mathrm{Q}_{347}$;

- $\mathrm{MVF}=0.25 \mathrm{Q}_{347}+75$;

- $\mathrm{MVF}=0.15 \mathrm{Q}_{347} /\left(\ln \mathrm{Q}_{347}\right)^{2}$. 
- For watercourses inhabited by salmon the values are increased by 0.004 $\mathrm{m}^{3} / \mathrm{s} / \mathrm{km}^{2}$.

In actual fact, these assessments were revised following changes in Spanish legislation from 2001 onwards.

The current Italian legislation (Decree Law $\mathrm{N}^{\circ} 152 / 06$ ), which fully implements the Water Framework Directive (WFD 2000/60/CE) issued by the European Community, calls for MVF estimation to be disciplined in the framework of the Water Protection Plan drawn up by the various regional governments. As a result, there are many proposed methods for estimating the MVF in Italy. Italy is approximately 1000 kilometres long from north to south and projects into the Mediterranean Sea. In the far north at the foot of the Alps lies the country's largest river basin, the Po river basin, while along the Apennine range we find many smaller basins, most of which are in a naturally torrential regime. Such a conformation gives rise to an immense number of microhabitats each with a biodiversity worthy of considerable environmental interest. This scenario justifies the chosen legislation, although it might seem to create confusion and uncertainty in estimating the MVF. For example, various formulations for estimating the MVF may have been determined for one and the same basin, even one as large as that of the river Po. Likewise, different formulations may be found for contiguous basins with apparently similar characteristics.

Italy - Po Basin Authority Study Commission for the Valtellina territory: the work of the Commission conducted on the results of a basin-wide campaign made it possible to determine the following assessment of the MVF:

- $\quad \mathrm{MVF}=\mathrm{Q}_{355}(\mathrm{Tr}=5$ years $) \cdot \mathrm{P} \cdot \mathrm{H} \cdot \mathrm{K}_{\mathrm{A}} \cdot \mathrm{K}_{\mathrm{NAT}}$ where:

$\mathrm{P}=$ mean annual rainfall;

$\mathrm{H}=$ mean basin elevation;

$\mathrm{K}_{\mathrm{A}}$ = increase coefficient due to natural beauty;

$\mathrm{K}_{\mathrm{NAT}}=$ increase coefficient due to wildlife.

Italy - Po Basin Authority: the Po Basin Authority provides a second assessment of the relation for estimating the MVF:

- $\quad \mathrm{MVF}=\mathrm{S} \cdot \mathrm{R}_{\mathrm{SPEC}} \cdot \mathrm{P} \cdot \mathrm{A} \cdot \mathrm{Q} \cdot \mathrm{N}$, where:

$\mathrm{S}=$ basin surface area;

$\mathrm{R}_{\mathrm{SPEC}}=0.0016 \mathrm{~m}^{3} / \mathrm{s}$;

$\mathrm{P}=$ rainfall in the basin (the greater they are, the greater the discharge will be);

$\mathrm{A}=$ mean basin elevation;

$\mathrm{Q}=$ biological quality of the water between catchment and discharge;

$\mathrm{N}=$ wildlife in the stretch between catchment and discharge to the river.

Italy - Lombardy Region: Regional Law $\mathrm{N}^{\circ}$ 6/42446 of 12 April 1999, in which the Lombardy Regional Government approved directives for evaluating applications for small catchments of water for hydroelectric uses, mentions in section 3.2 "Calculation of MVF" the Po Basin Authority's MVF formula:

- $\quad \mathrm{MVF}=1.6 \cdot \mathrm{P} \cdot \mathrm{A} \cdot \mathrm{Q} \cdot \mathrm{N} \cdot \mathrm{S}$ where:

$\mathrm{P}$ is the rainfall parameter variable between 1 (P lower than $1000 \mathrm{~mm}$ ), 1.4 (P between 1000 and $1400 \mathrm{~mm}), 1.8$ (P greater than $1400 \mathrm{~mm}$ ); 
$\mathrm{S}$ is the surface area in $\mathrm{Km}^{2}$ of the basin subtended by the catchment works (including the areas where catchment takes place upstream from the projected catchment area).

Factors $\mathrm{A}, \mathrm{Q}$ and $\mathrm{N}$ are considered to be equal to 1 , in the absence of specific data and in the current phase of experimentation. Exceptions to this include catchments within national parks, current or projected regional parks, nature reserves and natural monuments, local parks of wider geographical interest, areas of outstanding natural beauty or tourist designated areas, for which a value of $\mathrm{N}=2$ is adopted. A minimum objective for safeguarding small mountain watercourses is established by temporarily identifying a minimum flow at each catchment station, regardless of the subtended catchment basin, of $0.050 \mathrm{~m}^{3} / \mathrm{s}$ or the entire flow from upstream if below $0.050 \mathrm{~m} / \mathrm{s}$; if there are water tanks along the river, the minimum discharge of $0.050 \mathrm{~m}^{3} / \mathrm{s}$ must in any case be guaranteed.

\section{Analysis of the watercourse for catchment}

The watercourse chosen for the drinking water catchment study is the river Mingardo, the basin of which is located in the Campania region of southern Italy.

The Mingardo catchment basin covers approximately $223 \mathrm{~km}^{2}$, measures $25.95 \mathrm{~km}$ along its main stretch, and has a mean slope of $6.36 \%$, a maximum elevation $\mathrm{H}_{\mathrm{mx}}=1786 \mathrm{~m}$, and a mean elevation $\mathrm{H}_{\mathrm{md}}=566 \mathrm{~m}$. The catchment in question is located at the springs known as Fistole del Faraone, which discharge their flow into the Mingardo through a short secondary stretch.

Before calculating the MVF, therefore, we can estimate the mean flow that may be used for catchment purposes at the works, comprising an intake on the springs and a series of wells along the aquifer, which is compatible with the water balance of the structure supplying the Mingardo Basin. In particular, a mean flow from the catchment system equal to no more than $0.300 \mathrm{~m}^{3} / \mathrm{s}$ (drinking water requirement imposed by the civil users' basin and corresponding to slightly below $10 \cdot 10^{6} \mathrm{~m}^{3} /$ year) seems to be compatible with the aquifer.

Compatibility is assured by the fact that the flow is consistent with the mean flow values from the springs and that the Fistole del Faraone springs are supplied by the limestone hydrostructure of Monte Cervati-Monte Vesole which can ensure a mean effective infiltration volume of about $240 \cdot 10^{6} \mathrm{~m}^{3} /$ year. The sustainability of the required catchment volumes is confirmed by the mean yield value of this Hydrological Unit, which is $0.027 \mathrm{~m}^{3} / \mathrm{s} / \mathrm{km}^{2}$.

There is no historical data regarding water levels and peak flows for this basin. The Fistole del Faraone spring, which is characterised partly by regular water flows and partly by widespread water emergencies along the watercourse, has only been studied through the results of a hydrogeological survey campaign carried out by the former government agency "Cassa per il Mezzogiorno" throughout the period between January 1980 and December 1987. The measurements of the mean monthly flows taken immediately upstream of the spring and immediately downstream, make it possible to obtain the hydrograph of the flows in an average year in those stretches. The stretch upstream from the spring has a mean annual flow of $\mathrm{Q}_{\mathrm{uma}}=0.466 \mathrm{~m}^{3} / \mathrm{s}$, while downstream it is 
$\mathrm{Q}_{\mathrm{dma}}=1.006 \mathrm{~m}^{3} / \mathrm{s}$. It can therefore be deduced that the spring has a mean flow of $\mathrm{Q}_{\mathrm{sm}}=0.540 \mathrm{~m}^{3} / \mathrm{s}$. These measurements also make it possible to calculate the low water monthly flow over an average year: $\mathrm{Q}_{\mathrm{lm}}=0.262 \mathrm{~m}^{3} / \mathrm{s}$, while the historic minimum natural flow of $\mathrm{Q}_{\mathrm{mn}}=0.076 \mathrm{~m}^{3} / \mathrm{s}$ was recorded on 4 October 1982 .

It is also possible to estimate a mean summer flow (June, July, August and September of $\mathrm{Q}_{\mathrm{es}}=0.436 \mathrm{~m}^{3} / \mathrm{s}$; a mean flow for July and August of $\mathrm{Q}_{\mathrm{la}}=0.420$ $\mathrm{m}^{3} / \mathrm{s}$; and a mean flow for September and October of $\mathrm{Q}_{\text {so }}=0.401 \mathrm{~m}^{3} / \mathrm{s}$.

The MVF was thus estimated by means of the following relation, which is considered suitable for the Mingardo Basin and is similar to those adopted in hydrologically comparable Apennine basins (e.g. the river Magra) [14]:

- $\quad \mathrm{MVF}=\mathrm{S} \cdot \mathrm{R}_{\mathrm{SPEC}} \mathrm{P} \cdot \mathrm{A} \cdot \mathrm{Q} \cdot \mathrm{N} \cdot \mathrm{G} \cdot \mathrm{L}_{7.5}+\mathrm{M}_{10}$; where:

$\mathrm{S}$ is the basin surface area;

$\mathrm{R}_{\mathrm{SPEC}}$ (specific discharge) is $0.0016 \mathrm{~m}^{3} / \mathrm{s}$;

$\mathrm{P}$ (rainfall parameter) is variable between 1 (P lower than $1200 \mathrm{~mm}$ ) and 1.8 (P higher than $1800 \mathrm{~mm}$ );

A (elevation parameter) is variable between 1 (0-400 $\mathrm{m}$ above sea level), 1.1 (400-600 m above sea level), 1.2 (600-800 m above sea level), 1.3 (higher than $800 \mathrm{~m}$ above sea level);

$\mathrm{Q}$ (quality of the watercourse) is variable between 1 (unpolluted) and 1.4 (highly polluted) classified according to EBI biological quality;

$\mathrm{N}$ is the highest wildlife index in the relevant stretch and varies between 1 (built-up areas) and 1.8 (areas of outstanding natural beauty);

$\mathrm{G}$ (riverbed morphology) takes into account the relation between the shape and nature of the bed and the impact resulting from a reduction in the flow (the wider and flatter the riverbed, the greater the impact); preliminarily this is set to 1 ;

L 7.5 (length parameter) takes into account the distance between the measurement point and the return point and penalises returns over long stretches of the watercourse with lower flows; the increase in discharge is $7.5 \%$ for every kilometre between intake and discharge;

$\mathrm{M}_{10}$ (flow modulation) for the environmental need to guarantee a percentage of the natural flow variations present in the ecological cycle and affecting the wildlife in the river and along its banks, a flow is added equivalent to $10 \%$ of the difference between the natural flow and the MVF without modulation.

This process yielded MVF $=0.214 \mathrm{~m}^{3} / \mathrm{s}$. Bearing in mind the aleatory nature of the estimates made using such simplified methodologies, an element of control and assessment was introduced by processing data from a survey campaign carried out by the Cilento Vallo di Diano National Park Authority concerning river flows and speeds. Although limited, short and somewhat inhomogeneous, this campaign is significant in that it deals with a summer period with less rainfall and thus provides an opportunity for assessment and qualitative analysis.

Figure 1 reports a summary of the discharge measurements $\left(\mathrm{Q} \mathrm{m}^{3} / \mathrm{s}\right)$ taken in six cross sections during the indicated period ( $\mathrm{T}$ : date). The number 1 indicates the measurement cross section immediately upstream of the projected catchment 
works, while the number 2 indicates the cross section immediately downstream; the remaining cross sections are further downstream. Despite the brief period in which the measurements were taken, this data confirms the lack of flows during the summer months in the various measured cross sections of the watercourse, with values somewhat lower than those previously estimated. In this respect it can be observed that the measurements represent river discharge values that are incompatible with the above estimated MVF value.

The measurements for measurement cross sections 1 and 2 clearly and categorically highlight the problem of catchment works based on flow values measured in the river stretch.

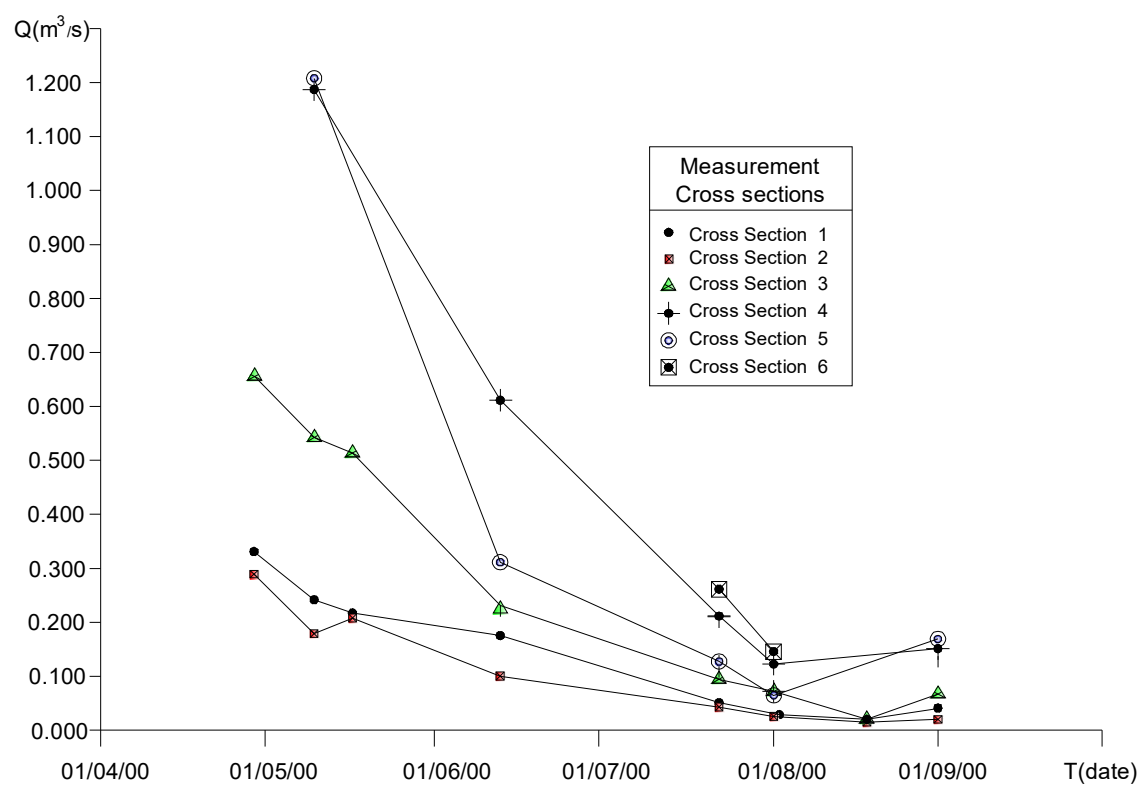

Figure 1: Discharge measurements.

\section{Conclusion}

A sustainable use of water as specified in current legislation makes it necessary to determine the MVF values for each month or season of the year. In this way, catchment and discharge operations ensure a constant residual flow in the riverbed that avoids variability in the natural flow regime on which the physical and biological equilibrium of the watercourse is based. Moreover, artificial regulation systems may be considered so that, in the case of torrential rivers, a part of the regulated volume can be used to bring the natural flow value closer to that of the MVF.

In the case examined here, the sustainability of the quantity destined for drinking water catchment is confirmed by the mean yield of the reference 
Hydrological Unit. Furthermore, the compatibility of the catchment flow is assured as it is consistent with the mean flow values for the springs.

It should be noted, however, that the flow measurements from the survey campaign conducted by the Cilento Vallo di Diano National Park Authority during summer months reported values that are somewhat lower than those estimated for the MVF and, therefore, incompatible with an optimal flow value for the habitat.

The problem raised by this incompatibility and conflict of interests may be solved by taking advantage of the fact that the catchment works draw water from the spring and from a series of wells connected to the aquifer. In actual fact, it is possible to envisage a catchment that meets the basin's drinking water requirements - by taking it from the spring - over a period that excludes the summer months which are characterised by a low water flow. This solution offers undeniable advantages in terms of energy costs as it would reduce the use of pumping stations.

Further benefits can be seen for the environmental conservation of the basin as it limits catchment to the period in which flows are greater and there is less demand for drinking water.

Finally, there is also the opportunity offered by this type of operation for the MVF to be sustained in periods of low water flow by using the underground aquifer as a water tank. Indeed, tapping the aquifer from the wells to feed the watercourse may ensure a flow in the watercourse that guarantees an optimal habitat for the affected species and, as has already been pointed out, this aquifer is fully able to satisfy such a requirement.

Although the proposed solution is specific to this context, it nevertheless constitutes a more general methodological approach in the context of climate change.

\section{References}

[1] Frega, G. \& Macchione, F. River quality requirements in determining stream flow, New trends in Water and Environmental Engineering for Safety and Life, Balkema, 2000.

[2] Meyer, J. L., Gibson, C. A., Poff, N. L., Georgakakos, A. P. \& Hay, L. E. Indicators of hydrologic alterations in response to a changing climate, Communication at the NABS Annual Meeting, Keystone, 2000.

[3] Olden, J. D. \& Poff, N. L. Redundancy and the choice of hydrologic indices for characterizing stream flow regimes, River Research Applications, 19, pp. 101-121, 2003.

[4] Poff, N. L. \& Ward, J. W. Implications of stream flow variability and predictability for lotic community structure: a regional analysis of stream flow patterns, Canadian Journal of Fisheries and Aquatic Sciences, 46(10), pp. 1805-1818, 1989.

[5] Poff, N. L., Allan, D., Bain, M. B., Karr, J. R., Prestegaard, K. L., Richter, B. D., Sparks, R. E. \& Stromberg, J. C. The natural flow regime. A 
paradigm for river conservation and restoration, BioScience, 47(11), pp. 769-784, 1997.

[6] Richter, B. D., Mathews, R., Harrison, D. L. \& Wigington, R. Ecologically sustainable water management: managing river flow for ecological integrity, Ecological Applications, 13(1), pp. 206-224, 2003.

[7] Principato, G. Basin water balance, Update Course on Protection against Pollution, Ed. Bios, pp. 385-405, 2004 (in Italian).

[8] Siligardi, M., Bernabei, S., Cappelletti, C., Chierici, E., Ciutti, F., Egaddi, F., Franceschini, A., Maiolini, B., Mancini, L., Minciardi, M. R., Monauni, C., Rossi, G. L., Sansoni, G., Spaggiari, R. \& Zanetti, M. River functionality indices (IFF), ANPA Manual, APAT Roma, 2000 (in Italian).

[9] Waddle, T. J. PHABSIM for Windows: User's Manual and Exercises, Fort Collins, Co, U.S., Geological Survey, 2002.

[10] The Nature Conservancy. Indicator of Hydrologic Alteration, Version 7 User's Manual, 2005.

[11] Binns, N. A. A Habitat Quality Index for Wyoming trout streams, Fishery Research Report, 2, Wyoming Game and Fish Department, pp. 75, 1979.

[12] Binns, N. A. Habitat Quality Index Procedures Manual, Wyoming Game and Fish Department, p. 209, 1982.

[13] Azzellino, A. \& Vismara, R. PQI Pool Quality Index, a new method to define the minimum flow requirements of high gradient low order streams, Journal of Environmental Engineering, ASCE, 127(11), pp. 1003-1013, 2001.

[14] Destra Sele Basin Authority, Provisional Hydrogeological Plan, Final Report, Regione Campania, Italy, 2002 (in Italian). 